\title{
Kinetics of Oxidative Degradation of Lignin-Based Phenolic Compounds in Batch Reactor
}

Filipa M. Casimiro, ${ }^{\dagger}$ Carina A. E. Costa, ${ }^{*} \dagger$ Cidália M. Botelho, ${ }^{\dagger}$ Maria F. Barreiro, $^{\ddagger}, \S$ and Alírio E. Rodrigues ${ }^{\dagger}{ }^{\circ}$

\begin{abstract}
${ }^{\dagger}$ Laboratory of Separation and Reaction Engineering-Laboratory of Catalysis and Materials (LSRE-LCM), Department of Chemical Engineering, Faculty of Engineering, University of Porto, Rua Dr. Roberto Frias s/n, 4200-465 Porto, Portugal

${ }^{\ddagger}$ Laboratory of Separation and Reaction Engineering-Laboratory of Catalysis and Materials (LSRE-LCM), Polytechnic Institute of Bragança, Campus Santa Apolónia, 1134, 5301-857 Bragança, Portugal

${ }^{\S}$ Centro de Investigação de Montanha (CIMO), Instituto Politécnico de Bragança, Campus de Santa Apolónia, 5300-253 Bragança, Portugal
\end{abstract}

\section{Supporting Information}

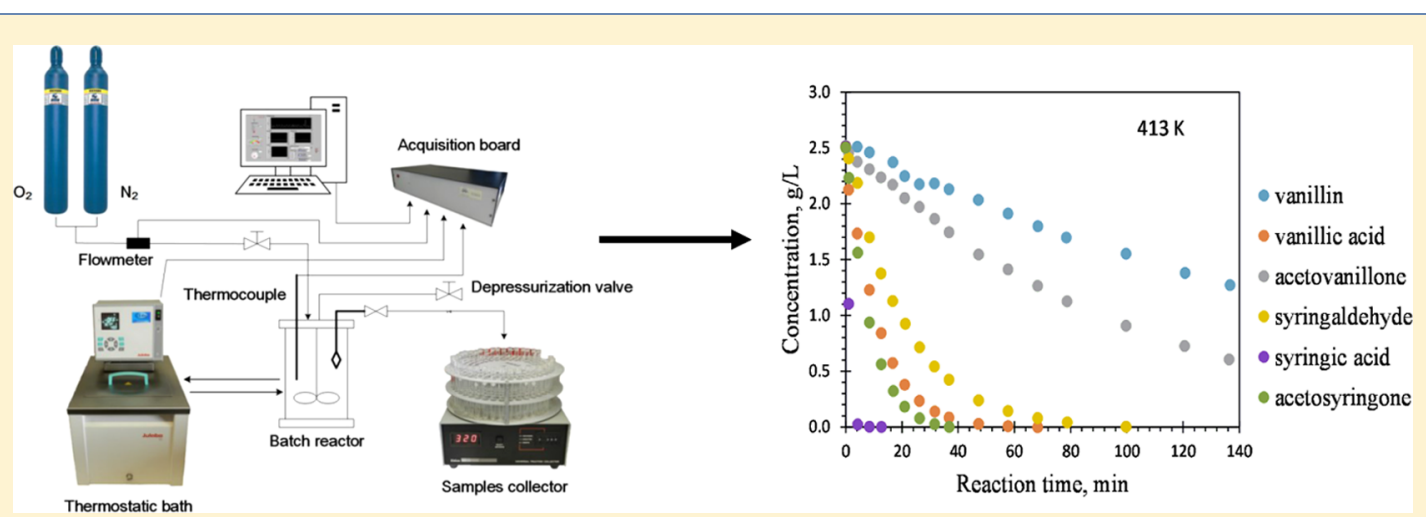

ABSTRACT: Vanillin, vanillic acid, acetovanillone, syringaldehyde, syringic acid, and acetosyringone are products obtained from lignin oxidation in an alkaline medium. The evaluation of their individual degradation under oxidation conditions mimicking lignin oxidation is an important tool to better understand this reaction and maximize the yield of target value-added products. In this context, the main objective of the present work was to study the kinetics of degradation of the selected ligninbased phenolic compounds. The effect of temperature, initial concentration, and oxygen partial pressure was evaluated, and a simple mathematical model was developed to describe the data from the degradation of the phenolics during oxidation reactions. The results indicate that, for all the evaluated compounds, the reaction order is first order with respect to both the initial phenolic compound concentration and oxygen concentration. A high degradation rate was found for the reactions performed at $413 \mathrm{~K}$, and an activation energy in the range of $53-86 \mathrm{~kJ} / \mathrm{mol}$ was found for all the studied phenolic compounds. Moreover, syringic acid is the phenolic compound more prone to degradation, while vanillin is the less one.

\section{INTRODUCTION}

Lignin is one of the most abundant renewable organic materials on earth, found in wood, annual plants, and other vascular tissues. ${ }^{1}$ It is a heterogeneous macromolecule mainly constituted by three basic units: p-cumaryl, coniferyl, and sinapyl alcohol. These monomers differ in the degree of substitution at the phenolic ring and are the precursors of the main moieties present in the lignin structure: $p$-hydroxyphenyl $(\mathrm{H})$, guaiacyl $(\mathrm{G})$, and syringyl $(\mathrm{S})$ units. $^{2}$ The ratio between $\mathrm{G}, \mathrm{S}$, and $\mathrm{H}$ units in lignin differs among the main groups of plants, namely, hardwood, softwood, and annual plants. ${ }^{3}$

Within lignocellulosic biorefineries, lignin conversion to value-added products, such as low-molecular-weight phenolic compounds, is one of the most straightforward and promising routes to expand lignin applications. In this context, oxidation has been the most studied method for lignin depolymeriza- tion. $^{4-9}$ The oxidative depolymerization of lignin involves the cleavage of aromatic rings, aryl ether linkages, and/or other linkages in the lignin structure. Lignin oxidation products range from aromatic aldehydes to carboxylic acids, depending on the lignin source and the harshness of the applied reaction conditions. 5,7,10 Among the possible routes, oxidation in alkaline medium with oxygen was the main method studied by our research group for lignin valorization. $6,7,11,12$

Vanillin (V), vanillic acid (VA), acetovanillone (VO), syringaldehyde (Sy), syringic acid (SA), and acetosyringone $\mathrm{SO}$ ) are the reaction products derived from lignin oxidation.

Received: May 23, 2019

Revised: August 2, 2019

Accepted: August 8, 2019

Published: August 8, 2019 
$\mathrm{V}$ is widely used as a flavoring and fragrance ingredient in food and cosmetic and a precursor for the synthesis of several second-generation fine chemicals and pharmaceuticals. ${ }^{13,14} \mathrm{VA}$, an oxidized form of $\mathrm{V}$, is most often used as a preservative in argan oil and as an acidity regulator in wine and vinegar. VO, also known as apocynin, is structurally related to $\mathrm{V}$ and has been studied due to its important pharmacological properties. $^{15-17}$ Sy is an organic compound occurring widely, in trace amounts, in nature. This phenolic is important in pharmaceutical applications due to its antioxidant, anti-inflammatory, antimicrobial, and antifungal properties. ${ }^{18} \mathrm{SA}$ is extensively used as a therapeutic, antioxidant, antimicrobial, antiinflammatory, and anticancer agent, ${ }^{19,20}$ while SO is a chemical compound related to acetophenone and is used as a plant hormone and insect attractor. ${ }^{21}$ Nowadays, great interest is focused on the achievement of eco-friendly processes to obtain $\mathrm{V}$ and Sy, as well as other related phenolic compounds (VA, $\mathrm{SA}, \mathrm{VO}$, and $\mathrm{SO}$ ). $\mathrm{V}$ production from the oxidation of lignin obtained from side streams of pulp and paper industries and biorefineries is widely studied and reported in literature. $^{6,7,11,22-26}$ Since the mid-1930s Tomlinson and Hibbert ${ }^{23}$ have reported the production of $\mathrm{V}$ from waste sulfite liquor using a hydrolysis procedure. In the same year, Sandborn and co-workers patented a process to produce $\mathrm{V}$ also by a hydrolysis process, but pointed out the need to use oxidation to achieve higher production yields. ${ }^{24}$ Mathias and Rodrigues reported the production of $\mathrm{V}$ by oxidation of kraft lignin with oxygen, as well as the effect of the operating process parameters (total pressure, temperature, oxygen partial pressure, lignin concentration, and sodium hydroxide concentration) on the kinetics of lignin oxidation reaction. ${ }^{27}$

In general, the improvement of the reaction yields of phenolics from lignin oxidation still needs a deeper knowledge about the behavior of each individual compound. In literature, there is a lack of studies that report the kinetic of oxidation of lignin-derived compounds in alkaline medium with oxygen and without heterogeneous catalyst. The main works published use oxidants like $\mathrm{H}_{2} \mathrm{O}_{2}$ or ozone and heterogeneous catalyst. $^{14,28-35}$ Sales and co-workers studied $\mathrm{V}$ degradation under similar experimental conditions as those used in this work but with a heterogeneous catalyst (palladium catalyst supported on $\gamma$-alumina). ${ }^{36}$ On the other hand, kinetics of $\mathrm{V}$ degradation using oxygen in alkaline medium $(\mathrm{NaOH})$ without the heterogeneous catalyst was investigated by Fargues and coworkers, who developed a kinetic model to evaluate the degradation of this phenolic compound. In the present work, an evaluation of the degradation of the main phenolic products derived from lignin oxidation (V, VA, VO, Sy, SA, and SO) was performed. The kinetic study considering these products individually is of great interest since during oxidation their formation can be simultaneously accompanied by their degradation process that is dependent on the applied oxidation conditions. Oxidation reactions were made in an alkaline medium $([\mathrm{NaOH}]=80 \mathrm{~g} / \mathrm{L} ; \mathrm{pH} \approx 14)$ with molecular oxygen, and the effect of temperature, oxygen partial pressure, and initial concentration of the phenolics was evaluated. A simple mathematical model was developed to describe the phenolic compounds degradation using general PROcess Modelling System software (gPROMS). The study was completed through the determination of activation energy $\left(E_{\mathrm{a}}\right)$ and reaction rate constants $(k)$ for all the studied lowmolecular-weight phenolic compounds.

\section{MATERIAL AND METHODS}

2.1. Chemicals. Phenolic compound standards (V, VA, VO, Sy, SA, and SO) were supplied by Sigma-Aldrich (Madrid, Spain), all of them with a purity grade higher than $95 \%$. Methanol (grade $\geq 99.8 \%$ ), formic acid (grade $\geq 99.9 \%$ ), and sodium hydroxide were provided from Merck (Darmstadt, Germany); oxygen (Alphagaz1 O2 L50, $10.6 \mathrm{~m}^{3}$ ) and nitrogen (Alphagaz1 N2 L50 $9.4 \mathrm{~m}^{3}$ ) were supplied from Air Liquid (Maia, Portugal).

2.2. Oxidation of Phenolic Compounds in Batch Reactor. Oxidation experiments were performed in a Büchi AG laboratory autoclave with a capacity of $1 \mathrm{~L}$ (model BEP280 type II, Switzerland). The heating and temperature control was assured by a Haake thermostatic bath (model N2-B, Karlsruhe, Germany). Temperature and total pressure inside the reactor were measured using a thermocouple type $\mathrm{K}$ and a pressure transducer (Kulite model XYME-190 M G, Leonia), respectively. The $\mathrm{O}_{2}$ flow rate was measured by means of a mass flow meter EL FLOW (Bronkhorst High-Tech B.V., model F-201C-FAC-11-V, Ruurlo, Netherlands) and expressed as standard cubic centimeters per minute. The reaction samples were collected at preset time intervals through an electrovalve (Asco Netherlands) assisted by a universal fraction collector Eldex (model 1243, Napa). The signals of the thermocouple, flow meter, and pressure transducer were recorded using an acquisition board and LabView program. Experimental setup is presented in Figure 1. For the oxidation

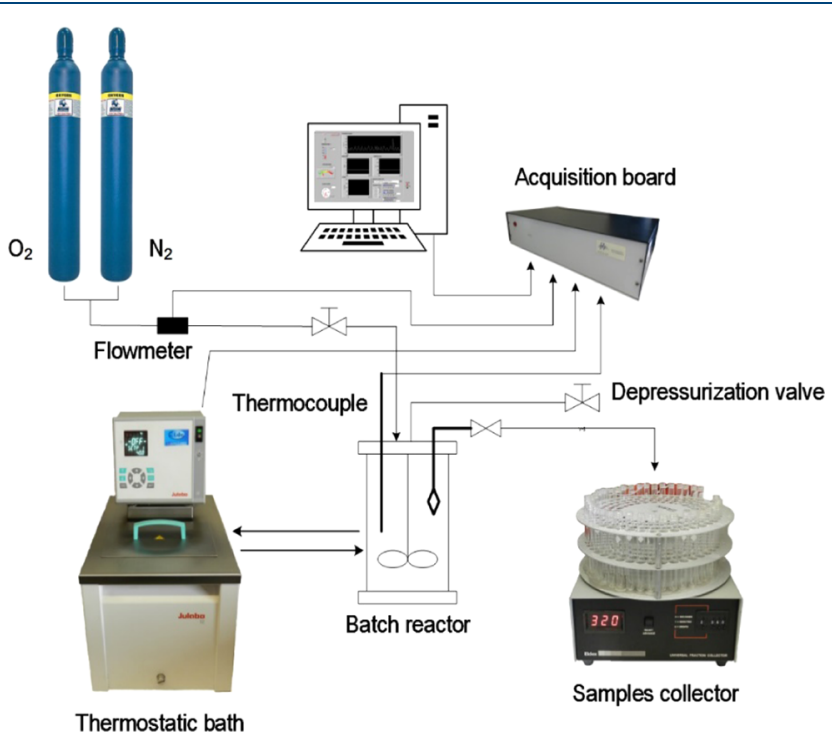

Figure 1. Experimental setup for kinetic studies of oxidation of ligninbased phenolic compounds.

reactions, a selected amount of each phenolic compound ( $\mathrm{V}$, VA, VO, Sy, SA, or SO) was dissolved in $500 \mathrm{~mL}$ of $\mathrm{NaOH}$ $(80 \mathrm{~g} / \mathrm{L})$ solution, introduced into the reactor, heated to the defined temperature, and pressurized. The reaction starts with the admission of $\mathrm{O}_{2}$. Samples from the reaction mixture were collected at regular time intervals. The analyses of the products were performed by the procedure and equipment/conditions as described in the following section.

2.3. High-Performance Liquid Chromatography (HPLC) Analysis. Quantification of V, VA, VO, Sy, SA, and SO was made by high-performance liquid chromatography (HPLC), as described elsewhere. ${ }^{37}$ A Knauer HPLC system 
(a)

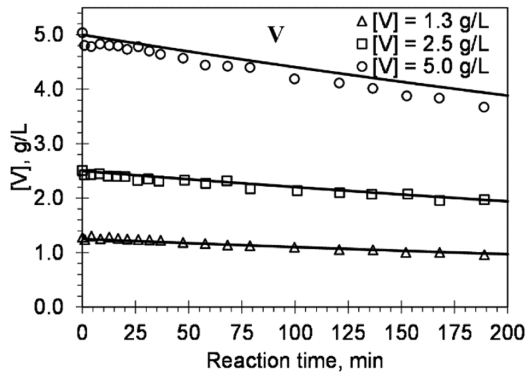

(b)

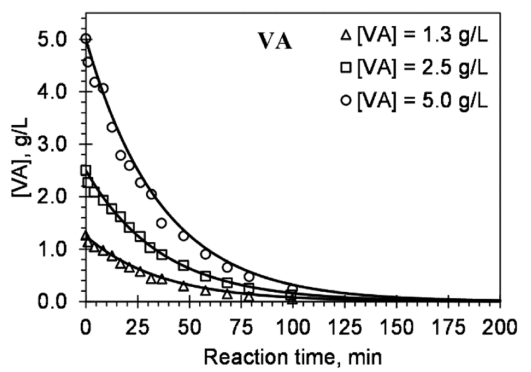

(c)

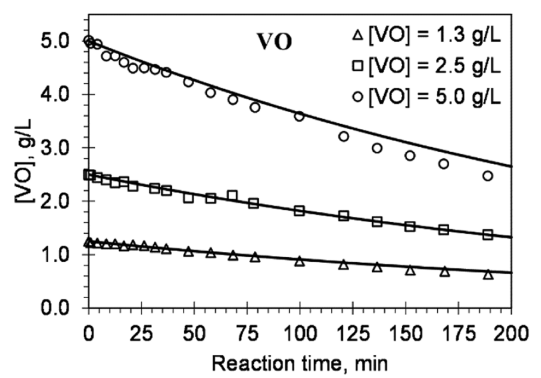

(d)

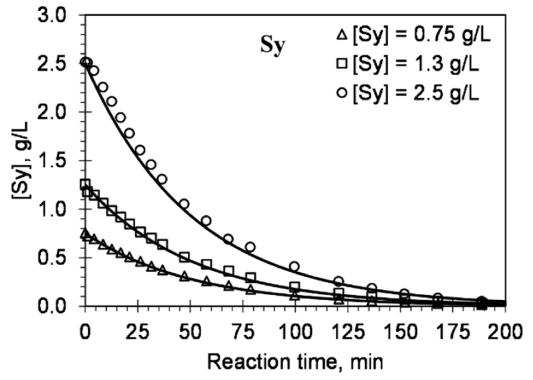

(e)

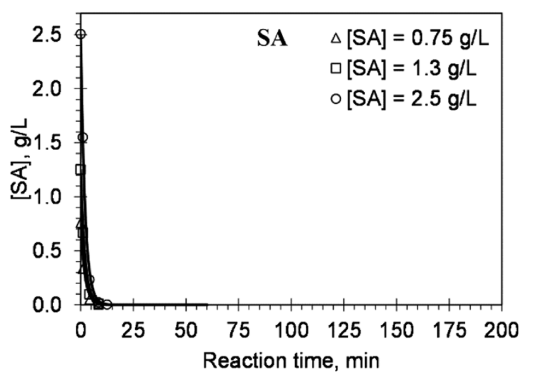

(f)

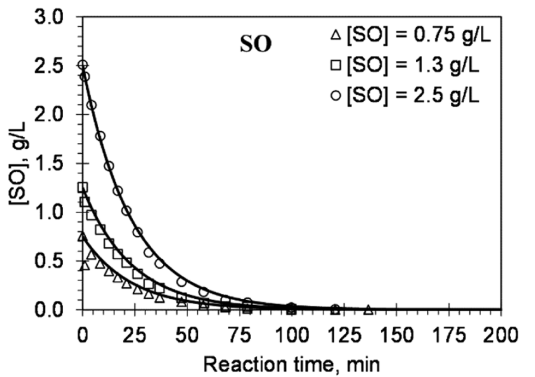

Figure 2. Effect of initial concentration on the degradation along oxidation reaction time: (a) V, (b) VA, (c) VO, (d) Sy, (e) SA, (f) SO, and the line represents the fitted kinetic model $(-)$. Initial reaction conditions: $[\mathrm{NaOH}]=80 \mathrm{~g} / \mathrm{L} ; \mathrm{pH} \approx 14 ; T_{\mathrm{i}}=393 \mathrm{~K} ; p \mathrm{O}_{2}=3$ bar; $P_{\mathrm{T}}=9.8$ bar.

equipped with a Smartline 5000 online degasser, a Smartline 1000 quaternary pump, and a Smartline 2600 UV-DAD detector was used. The analytical column was an ACE 5 C18pentafluorophenyl group $(250 \times 3.0 \mathrm{~mm}, 5 \mu \mathrm{m})$ with a guard column of the same material. The detection wavelength was set to $280 \mathrm{~nm}$ and the injection volume was $20 \mu \mathrm{L}$. Chromatograms were acquired at $30{ }^{\circ} \mathrm{C}$ with a flow rate of $0.6 \mathrm{~mL} / \mathrm{min}$ using an elution gradient composed of two eluents: (A) methanol/water (5:95\% v/v) and (B) methanol/water (95:5\% $\mathrm{v} / \mathrm{v})$, both acidified with formic acid $(0.1 \% \mathrm{v} / \mathrm{v})$. The elution gradient was [0-3.30] min $90 \%$ A; $6.70 \mathrm{~min} 80 \% \mathrm{~A}$; [6.7020] $\min 80 \% \mathrm{~A} ; 35 \mathrm{~min} 50 \% \mathrm{~A} ; 38.3 \mathrm{~min} 0 \% \mathrm{~A}$; [38.3-41.7] min 0\% A; 45 min 90\% A; [45-55] min 90\% A. Quantification of all compounds was done based on calibration curves previously prepared from standard solutions in the needed concentration range.

\section{RESULTS AND DISCUSSION}

3.1. Kinetic Analysis of V, VA, VO, Sy, SA, and SO Degradation. The understanding of the reaction pathways for lignin oxidation can be improved through a preliminary study of the oxidation of model compounds. ${ }^{32}$ Mathias ${ }^{11}$ developed a simple model for $\mathrm{V}$ oxidation in alkaline medium with oxygen, while Fargues et al. ${ }^{38}$ reported a kinetic study of $\mathrm{V}$ oxidation using the same conditions.
In this work, the proposed mechanism for V, VA, VO, Sy, $\mathrm{SA}$, and $\mathrm{SO}$ oxidation in alkaline medium with oxygen is based on previously published works. ${ }^{11,12,32,38}$ Considering the proposed mechanism, phenolics are dissolved in an alkaline medium to guarantee a high $\mathrm{pH}(\approx 14)$, which implies that the phenolics dissociate into ionic forms and thus react with molecular oxygen. The oxidation of phenolics results from the action of $\mathrm{HOO}^{\bullet}$ or $\mathrm{O}_{2}^{-}$radicals on the radical $\mathrm{A}^{\bullet}$, or from the direct action of molecular oxygen. The degradation mechanism of the phenolic compound A, which can be V, VA, VO, Sy, SA, or $\mathrm{SO}$, can be represented as

$$
\begin{aligned}
& \text { initiation } \mathrm{AH}+\mathrm{O}_{2} \rightarrow \mathrm{A}+\mathrm{HOO} \\
& \text { propagation } \mathrm{A}+\mathrm{O}_{2} \rightarrow \mathrm{AOOAOO}+\mathrm{AH} \\
& \rightarrow \mathrm{AOOH}+\mathrm{A} \\
& \text { termination } \mathrm{AOO}+\mathrm{AOO} \rightarrow \text { products }
\end{aligned}
$$

The equation used to relate the reaction rate with the phenolic compound concentration and oxygen concentration in the liquid phase, $\left[\mathrm{O}_{2}^{\mathrm{liq}}\right]$, is presented below

$$
r_{\mathrm{A}}=k[\mathrm{~A}]^{n}\left[\mathrm{O}_{2}^{\mathrm{liq}}\right]^{m}
$$

where $r_{\mathrm{A}}$ is the reaction rate of the phenolic compound, [A] is the phenolic concentration ( $\mathrm{V}, \mathrm{VA}, \mathrm{VO}, \mathrm{Sy}, \mathrm{SA}$, or $\mathrm{SO}), k$ is 
(a)

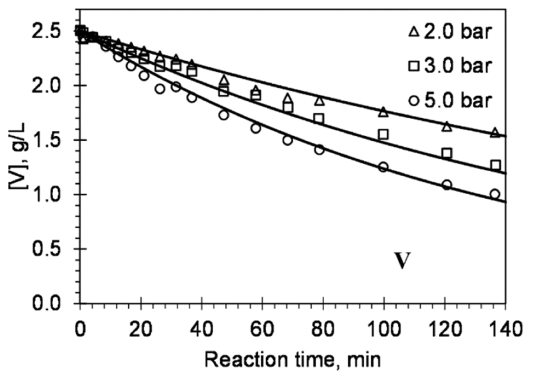

(b)

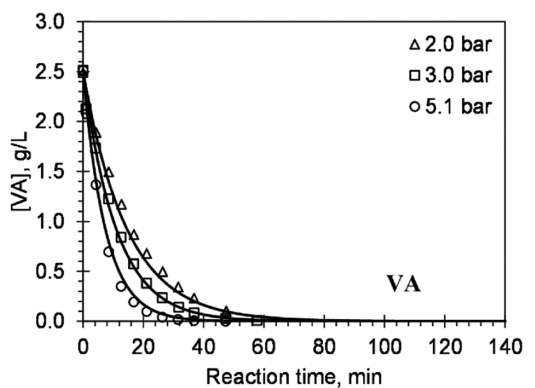

(c)

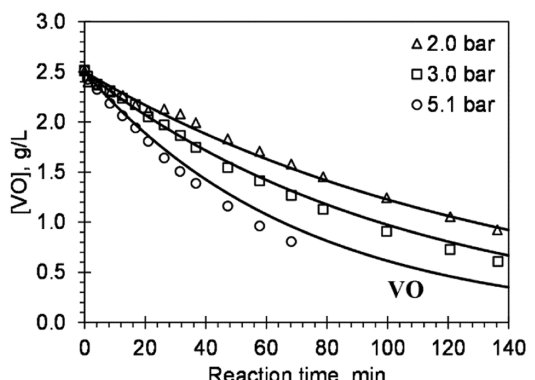

(d)

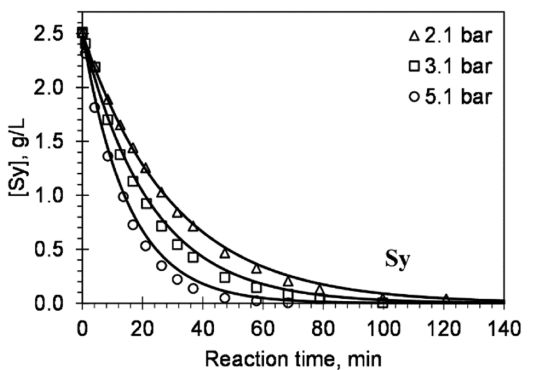

(e)

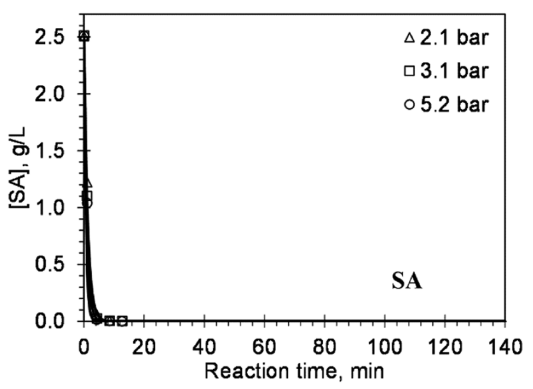

(f)

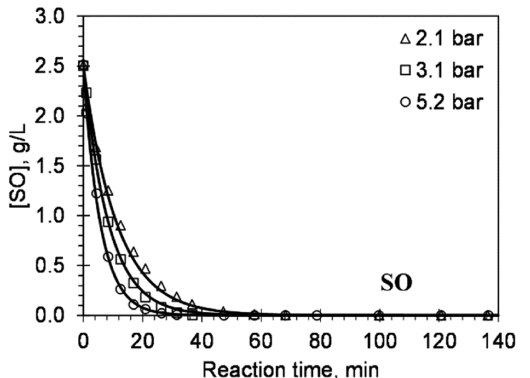

Figure 3. Effect of oxygen partial pressure on the degradation as a function of reaction time: (a) V, (b) VA, (c) VO, (d) Sy, (e) SA, (f) SO, and the line represents the fitted kinetic model $(-)$. Initial reaction conditions: $[\mathrm{NaOH}]=80 \mathrm{~g} / \mathrm{L}$; $\mathrm{pH} \approx 14$; initial concentration of compounds $2.5 \mathrm{~g} / \mathrm{L}$; $T_{\mathrm{i}}=413 \mathrm{~K} ; P_{\mathrm{T}}=9.8$ bar.

the oxidation rate constant, and $n$ and $m$ are the reaction orders with respect to initial $[\mathrm{A}]$ and $\left[\mathrm{O}_{2}^{\text {liq }}\right]$, respectively. The values of $\mathrm{pO}_{2}$ of the gas phase were converted to the concentration of $\mathrm{O}_{2}$ in the liquid phase using a correlation published by Mathias $^{11}$ (eq 2).

$$
\begin{array}{r}
{\left[\mathrm{O}_{2}^{\mathrm{liq}}\right]=\left(3.559-6.659 \times 10^{-3} \times \mathrm{T}-5.606 \times p \mathrm{O}_{2}\right.} \\
+1.594 \times 10^{-5} \times p \mathrm{O}_{2} \times T^{2}+1.498 \times 10^{3} \\
\left.\times \frac{p \mathrm{O}_{2}}{T}\right) \times\left(10^{-0.144 \times I}\right) \times\left(10^{-3}\right) \mathrm{in} \mathrm{mol} / \mathrm{L}
\end{array}
$$

where $I$ is the ionic strength of the solvent in mol/L. The kinetic model developed was applied to describe the degradation of phenolic compounds in batch reactor during oxidation. The model was solved using general PROcess Modelling System (gPROMS) (PSA Enterprise, U.K.), and the differential-algebraic equation SOLVer (DASOLV) was used to solve the ordinary differential equation in time. To develop the model, different assumptions were considered: (a) isothermal conditions, (b) perfectly mixed reactor, (c) constant liquid and gas volumes, (d) closed system with respect to the liquid phase, (e) constant total pressure, (f) negligible mass transfer resistances, and ( $g$ ) irreversible degradation reactions. The material balance, described in eq 3 , is defined taking into account the previous assumptions

$$
\frac{\mathrm{d}[\mathrm{A}]}{\mathrm{d} t}=-r_{\mathrm{A}}
$$

where $t$ is the reaction time. Since the starting liquid mixture consists of an aqueous alkaline solution of the phenolic compound with known concentration, the initial conditions for the material balance are $t=0$ and $[\mathrm{A}]=[\mathrm{A}]_{\mathrm{i}}$, where $[\mathrm{A}]_{\mathrm{i}}$ is the initial concentration of each phenolic. The performed oxidation reactions were simulated, fitting the developed kinetic model to the experimental data, and the results are presented in the following sections. Moreover, it can be stated that the developed kinetic model fits all the experimental results concerning the oxidation reactions of the phenolic compounds.

3.2. Effect of the Phenolic Initial Concentration. The effect of the initial concentration on the degradation of the selected phenolic compounds (V, VA, VO, Sy, SO, and SA) was evaluated though different oxidation reactions performed at constant temperature, $T=393 \mathrm{~K}$, constant oxygen partial pressure, $p \mathrm{O}_{2}=3.1 \mathrm{bar}$, and constant total pressure, $P_{\mathrm{T}}=9.8$ bar. The initial concentration of each phenolic compound ranged between 1.3 and $5.0 \mathrm{~g} / \mathrm{L}$ for $\mathrm{V}, \mathrm{VA}$, and $\mathrm{VO}$ and 
(a)

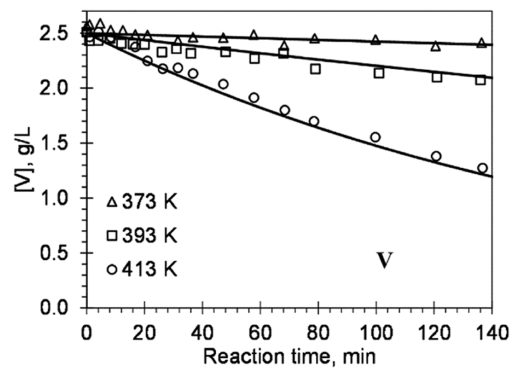

(b)

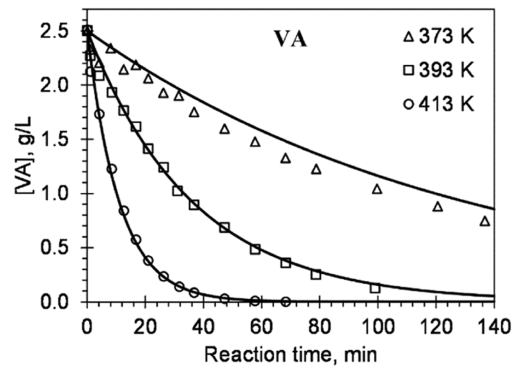

(c)

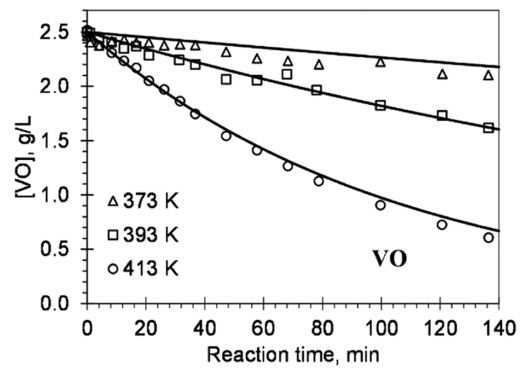

(d)

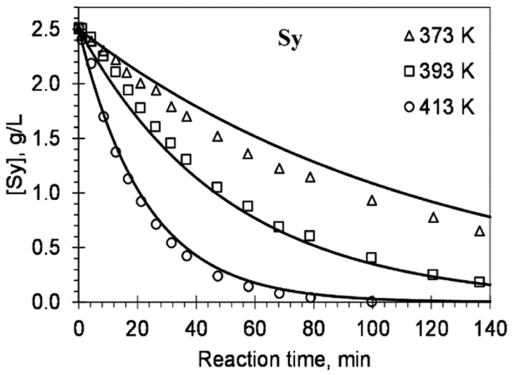

(e)

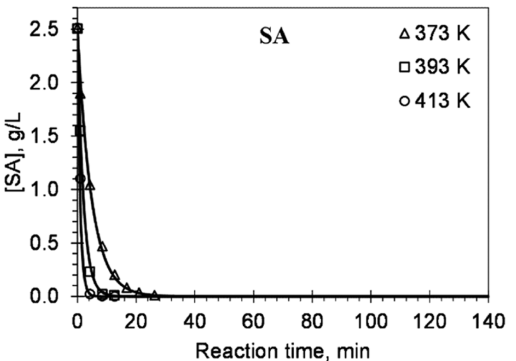

(f)

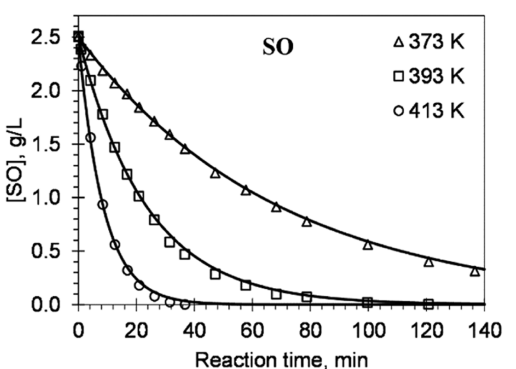

Figure 4. Effect of temperature on the degradation as a function of oxidation reaction time: (a) V, (b) VA, (c) VO, (d) Sy, (e) SA, (f) SO, and the line represents the fitted kinetic model $(-)$. Initial reaction conditions: $[\mathrm{NaOH}]=80 \mathrm{~g} / \mathrm{L} ; \mathrm{pH} \approx 14$; initial concentration of compound $2.5 \mathrm{~g} / \mathrm{L}$; $p \mathrm{O}_{2}=3.0$ bar; $P_{\text {total }}=9.8$ bar.

between 0.75 and $2.5 \mathrm{~g} / \mathrm{L}$ for Sy, SA, and SO. The alkaline medium contained a $[\mathrm{NaOH}]=80 \mathrm{~g} / \mathrm{L}$. The solubility of each compound influenced the selected concentration range, reason why the derivatives from $S$ units were tested at lower initial concentrations than the $\mathrm{G}$ units derivatives.

Figure 2 shows the effect of initial concentration on the degradation yield for each studied phenolic compound. For V, $\mathrm{VA}$, and VO, it was verified that the initial concentration does not affect the degradation yields. After $100 \mathrm{~min}$ of reaction time, $\mathrm{V}$ has a degradation level between 14 and 17\%, independent of the used initial concentration. After the same reaction time, VA shows a complete degradation in all the performed oxidation reactions, being the most reactive compound considering $\mathrm{G}$ units derivatives. VO shows a degradation level between 23 and $28 \%$ for the performed oxidation reactions, which means that the initial concentration does not significantly affect its degradation. In a previous study addressing the kinetics of $\mathrm{V}$ oxidation, Fargues and co-workers also stated that the initial concentration does not affect the $\mathrm{V}$ degradation yield, i.e., the degradation is almost the same independent of the tested initial concentration. ${ }^{38}$

Concerning Sy, SA, and SO, a similar behavior was observed; the initial concentration of these phenolic compounds does not impact their degradation yield. Sy shows a degradation of around $84 \%$ after 100 min of reaction time, independent of the used initial concentration. SA appears to be a very reactive compound, with a complete degradation in less than $15 \mathrm{~min}$ for all the experimental oxidation conditions. SO also showed a complete degradation whatever the used initial concentration, but only after surpassing a reaction time of $100 \mathrm{~min}$.

3.3. Effect of Oxygen Partial Pressure. To evaluate the effect of the oxygen partial pressure, $\mathrm{pO}_{2}$ on the degradation of phenolic compounds (V, VA, VO, Sy, SA, SO) during oxidation in batch reactor, oxidation reactions were performed in alkaline medium, $[\mathrm{NaOH}]=80 \mathrm{~g} / \mathrm{L}$, at constant total pressure, $P_{\mathrm{T}}=9.8 \mathrm{bar}$, constant temperature, $T=413 \mathrm{~K}$, and constant initial concentration of the phenolic compound, 2.5 $\mathrm{g} / \mathrm{L}$. The tested $\mathrm{pO}_{2}$ was 2.0, 3.1, and 5.1 bar.

The concentration of V, VA, VO, Sy, SA, and SO versus reaction time for each oxidation performed with different $\mathrm{pO}_{2}$ levels is shown in Figure 3. The results indicated that VA, Sy, $\mathrm{SA}$, and $\mathrm{SO}$ have a complete degradation after $80 \mathrm{~min}$ of reaction, independent of the used $p \mathrm{O}_{2}$. In the case of $\mathrm{V}$ and $\mathrm{VO}$, the degradation was not complete even after $140 \mathrm{~min}$ of reaction, independent of the used $p \mathrm{O}_{2}$. Moreover, in the reaction conducted under a $p \mathrm{O}_{2}$ of $5 \mathrm{bar}, 44 \%$ of the initially used $\mathrm{V}$ was degraded after $80 \mathrm{~min}$, while for the reactions using 
(a)

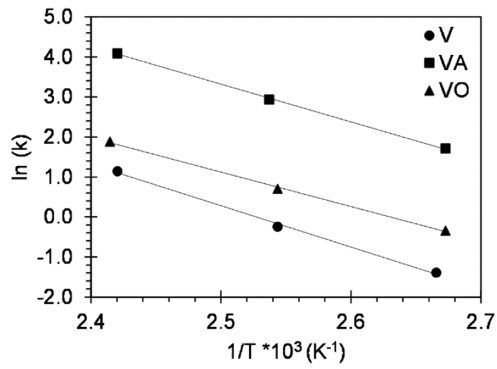

(b)

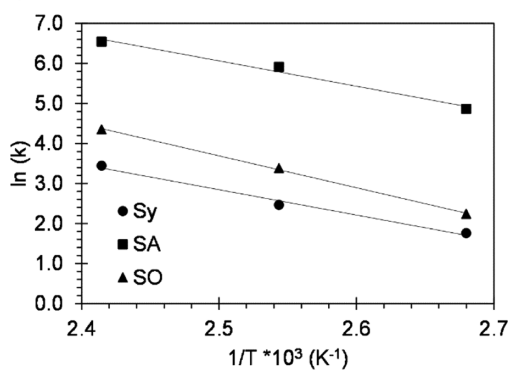

Figure 5. Arrhenius plot, logarithm of $k$ versus $1 / T$, for the calculation of the activation energy of (a) V, VA, VO and (b) Sy, SA, SO oxidation.

Table 1. Summary of Activation Parameters for V, VA, VO, Sy, SA, and SO Oxidation in an Alkaline Medium

\begin{tabular}{lllllll} 
& \multicolumn{1}{c}{ V } & \multicolumn{1}{c}{ VA } & \multicolumn{1}{c}{ VO } & \multicolumn{1}{c}{ Sy } & \multicolumn{1}{c}{ SA } & \multicolumn{1}{c}{ SO } \\
$\boldsymbol{E}_{\mathrm{a}}, \mathrm{kJ} / \mathrm{mol}$ & $86.0 \pm 1$ & $78.4 \pm 1$ & $71.6 \pm 1$ & $52.7 \pm 1$ & $52.7 \pm 1$ & $66.2 \pm 1$ \\
$\boldsymbol{E}_{\mathrm{a}} / \boldsymbol{R}$ & -10348 & -9427 & -8610 & -6336 & -6335 & -7956 \\
$\boldsymbol{k}_{\mathbf{0}}$ & $2.27 \times 10^{11}$ & $4.75 \times 10^{11}$ & $6.84 \times 10^{9}$ & $1.30 \times 10^{8}$ & $3.25 \times 10^{9}$ & $1.74 \times 10^{10}$
\end{tabular}

$p \mathrm{O}_{2}$ of 3 and 2 bar, for the same reaction time, 32 and $26 \%$ of degradation was obtained, respectively. Considering VO, it was also observed that the increase in $\mathrm{pO}_{2}$ enhances the degradation of this phenolic; in the reaction with 2 bar of $\mathrm{pO}_{2}$, only $42 \%$ of the initial VO was degraded after $80 \mathrm{~min}$, comparatively with 55 and $70 \%$ when 3 and 5 bar of $\mathrm{pO}_{2}$ were used, respectively. In general, the increase of $p \mathrm{O}_{2}$ led to an increase in the degradation of the phenolic compound.

3.4. Effect of Temperature on the Reaction Rate. In this series of experiments, oxidation of $\mathrm{V}, \mathrm{VA}, \mathrm{VO}, \mathrm{Sy}, \mathrm{SA}$, and SO were performed in an alkaline medium, $[\mathrm{NaOH}]=80 \mathrm{~g} / \mathrm{L}$, at a constant total pressure, $P_{\mathrm{T}}=9.8 \mathrm{bar}$, constant oxygen partial pressure, $p \mathrm{O}_{2}=3.1$ bar (except for Sy, SA, and SO, $p \mathrm{O}_{2}$ $=3.0 \mathrm{bar}$ ), and an initial concentration of $2.5 \mathrm{~g} / \mathrm{L}$. Temperature was 373,393 , and $413 \mathrm{~K}$.

The results showed that the increase of temperature enhanced the degradation of all studied phenolic compounds (Figure 4). When an initial $T$ of $413 \mathrm{~K}$ was used, a degradation of 24,100 , and $39 \%$ was found for V, VA, and VO, respectively, after $1 \mathrm{~h}$ of reaction. It can also be observed that VA is the compound most susceptible to degradation, with $41 \%$ of degradation before $60 \mathrm{~min}$ of reaction when an initial temperature of $373 \mathrm{~K}$ was used.

At a temperature of $413 \mathrm{~K}$, a complete degradation of SA and $\mathrm{SO}$ at the end of the reaction time of $1 \mathrm{~h}$ and a degradation of $94 \%$ of Sy were observed. Lower degradations were detected when a temperature of $373 \mathrm{~K}$ was used, achieving a degradation of 46,100 , and $57 \%$ for Sy, SA, and $\mathrm{SO}$, respectively, after $1 \mathrm{~h}$ of reaction time.

In the oxidation of phenolic ketones (VO and SO), a small amount of the corresponding phenolic aldehydes, V and Sy, respectively, were produced. This is most noticeable when the reactions are performed using an initial temperature of $413 \mathrm{~K}$. Fung and Hrutfiord ${ }^{39}$ published a patent concerning the alkaline oxidation of $\mathrm{VO}$ to produce $\mathrm{V}$, where it was stated that the applied reaction conditions affected the conversion yield. Alunga and co-workers have also reported V and Sy formation through VO and SO oxidation, respectively. ${ }^{32}$ The authors used $\mathrm{CuSO}_{4}$ as the catalyst on the oxidation reactions concluding that the rate of $\mathrm{V}$ formation increases with the use of higher temperatures.

3.5. Kinetic Parameters. The kinetic parameters used to develop the model that fits the experimental data are described in detail in Section 3.1. The reaction orders, $n$ and $m$, from eq 1 , were determined from the slope of the logarithmic representation of $r_{0}$ (initial reaction rate for different $T$ ) as a function of the logarithmic phenolic initial concentration and logarithmic $\left[\mathrm{O}_{2}^{\text {liq }}\right]$, respectively (Supporting Information). The results showed that, for all the studied phenolics, V, VA, VO, Sy, SA, and SO, the reaction order with respect to the phenolic initial concentration was 1 . The first-order dependence was also obtained for $\left[\mathrm{O}_{2}^{\mathrm{liq}}\right]$. Fargues and co-workers have also found a reaction order of 1 with respect to $\mathrm{V}$ concentration and to $\left[\mathrm{O}_{2}^{\text {liq }}\right]$, whereas Alunga and co-workers reported that the kinetic reaction for $\mathrm{VO}$ degradation was also of first order. ${ }^{32,38}$

The equation describing the reaction kinetics for any of the compound A studied, V, VA, VO, Sy, SA, and SO, is given by

$$
r_{\mathrm{A}}=k[\mathrm{~A}]^{1}\left[\mathrm{O}_{2}^{\mathrm{liq}}\right]^{1} \text { in } \mathrm{g} /(\mathrm{L} / \mathrm{min})
$$

As stated before, temperature has a significant impact on phenolic compounds degradation and its dependence can be explained by the Arrhenius equation, eq 4, which was applied for the determination of kinetic parameters.

$$
k=k_{0} \mathrm{e}^{-E_{\mathrm{a}} / R T}
$$

where $T$ is the absolute temperature $(\mathrm{K}), k_{0}$ is the preexponential factor, $E_{\mathrm{a}}$ is the activation energy for the reaction $(\mathrm{J} / \mathrm{mol})$, and $R$ is the universal gas constant. Equation 4 can be linearized as

$$
\ln (k)=\ln \left(k_{0}\right)-\frac{E_{\mathrm{a}}}{R T}
$$

The Arrhenius plot, $\ln (k)$ versus $1 / T$, for V, VA, VO and Sy, $\mathrm{SA}$, SO degradation kinetics is presented in Figure 5. The slope from the graphic representation of the logarithm of $k(T)$ as a function of $1 / T$ allows to determine $E_{a}$ for each phenolic compound.

Table 1 summarizes the obtained activation parameters for V, VA, VO, Sy, SA, and SO oxidation in an alkaline medium with oxygen. The calculated $E_{\mathrm{a}}$ values for $\mathrm{V}(86.0 \mathrm{~kJ} / \mathrm{mol})$ is similar to the one determined by Fargues and co-workers or Wallick and Sarkanen. ${ }^{38,40}$ Also, Alunga and co-workers reported in a study about VO degradation with a heterogeneous catalyst a $E_{\mathrm{a}}$ value of $85.3 \mathrm{~kJ} / \mathrm{mol}$, similar to that obtained in this work. ${ }^{32}$ Kalyani and Jamunarani 
investigated Sy oxidation with hexacyanoferrate(III) in an alkaline medium and reported a $E_{\mathrm{a}}$ of $48.40 \mathrm{~kJ} / \mathrm{mol}^{41}$

Concerning the reaction rates, in a general way, the results show that with increase in the initial concentration, $p \mathrm{O}_{2}$ or $T$ enhanced the initial reaction rate for all the studied phenolic compounds. The reaction rate range varies between $9.39 \times$ $10^{-3}$ and $1.34 \mathrm{~g} /(\mathrm{L} / \mathrm{min})$. The phenolic presenting the highest degradation reaction rate was $\mathrm{SA}$, whereas the one with the lowest reaction rate was $\mathrm{V}$.

\section{CONCLUSIONS}

The study of the degradation of valuable phenolic compounds obtained from lignin oxidation in an alkaline medium with $\mathrm{O}_{2}$ was the main objective of this work. The performed kinetic study allowed the evaluation of the reaction orders with respect to the initial concentrations of V, VA, VO, Sy, SA, and SO and oxygen concentration, as well as the effect of temperature on the kinetic rate constants. The results showed that the initial concentration of phenolic compounds as well as the oxygen concentration had no effect on the degradation reaction rate, since a first-order dependence for both oxidation parameters was obtained for all the studied compounds. The developed pseudo-first-order model fits well all the experimental data, considering the oxidative degradation of the studied phenolic compounds. The activation parameters were calculated, achieving activation energy in the range of $53-86 \mathrm{~kJ} / \mathrm{mol}$ found for V, VA, VO, Sy, SA, and SO. Comparing all the tested phenolic, it was possible to conclude that Sy, SA, and SO have higher degradation rates in comparison with V, VA, and VO. This is an expected behavior since derivatives from $\mathrm{S}$ units are more reactive than the ones from $\mathrm{G}$ due to the presence of two methoxyl groups in the aromatic ring in the later compounds.

\section{ASSOCIATED CONTENT}

\section{S Supporting Information}

The Supporting Information is available free of charge on the ACS Publications website at DOI: 10.1021/acs.iecr.9b02818.

Logarithmic representation of initial reaction rate versus logarithmic initial concentration of vanillin, vanillic acid, acetovanillone, syringaldehyde, syringic acid, and acetosyringone (Figures S1-S6) (PDF)

\section{AUTHOR INFORMATION}

\section{Corresponding Author}

*E-mail: caecosta@fe.up.pt. Tel.: +351220413658.

\section{ORCID}

Carina A. E. Costa: 0000-0001-5136-3803

Alírio E. Rodrigues: 0000-0002-0715-4761

Notes

The authors declare no competing financial interest.

\section{ACKNOWLEDGMENTS}

This work is a result of Project “AIProcMat@N2020Advanced Industrial Processes and Materials for a Sustainable Northern Region of Portugal 2020", with the reference NORTE-01-0145-FEDER-000006, supported by Norte Portugal Regional Operational Programme (NORTE 2020), under the Portugal 2020 Partnership Agreement, through the European Regional Development Fund (ERDF); Associate Laboratory LSRE-LCM-UID/EQU/50020/2019-funded by national funds through FCT/MCTES (PIDDAC) and
Foundation for Science and Technology (FCT, Portugal). CIMO (UID/AGR/00690/2019) through FEDER under Program PT2020.

\section{REFERENCES}

(1) Rodrigues, A.; Pinto, P.; Barreiro, F.; Costa, C. A. E.; Mota, M. I. F.; Fernandes, I. An Integrated Approach for Added-Value Products from Lignocellulosic Biorefineries, 1st ed.; Springer International Publishing, Springer Nature: Switzerland, AG, 2018; p 166.

(2) Fratini, E.; Bonini, M.; Oasmaa, A.; Solantausta, Y.; Teixeira, J.; Baglioni, P. SANS Analysis of the Microstructural Evolution during the Aging of Pyrolysis Oils from Biomass. Langmuir 2006, 22, 306312.

(3) Scott, J. L.; Buchard, A. 17 - Polymers from Plants: Biomass Fixed Carbon Dioxide as a Resource. In Managing Global Warming; Letcher, T. M., Ed.; Academic Press, 2019; pp 503-525.

(4) Pinto, P. C. R.; da Silva, E. A. B.; Rodrigues, A. E. Lignin as Source of Fine Chemicals: Vanillin and Syringaldehyde. In Biomass Conversion: The Interface of Biotechnology, Chemistry and Materials Science; Baskar, C., Baskar, S., Dhillon, S. R., Eds.; Springer: Berlin, 2012; pp 381-420.

(5) Pinto, P. C. R.; da Silva, E. A. B.; Rodrigues, A. E. Insights into Oxidative Conversion of Lignin to High-Added-Value Phenolic Aldehydes. Ind. Eng. Chem. Res. 2011, 50, 741-748.

(6) Araújo, J. D. P. Production of Vanillin from Lignin Present in the Kraft Black Liquor of the Pulp and Paper Industry; Faculty of Engineering University of Porto: Porto, 2008.

(7) Pinto, P. C. R.; Costa, C. E.; Rodrigues, A. E. Oxidation of Lignin from Eucalyptus globulus Pulping Liquors to Produce Syringaldehyde and Vanillin. Ind. Eng. Chem. Res. 2013, 52, 44214428.

(8) Mathias, A. L.; Lopretti, M. I.; Rodrigues, A. Chemical and biological oxidation of Pinus pinaster lignin of the production of vanillin. J. Chem. Technol. Biotechnol. 1995, 64, 225-234.

(9) Ma, R.; Guo, M.; Zhang, X. Recent advances in oxidative valorization of lignin. Catal. Today 2018, 302, 50-60.

(10) Pandey, M. P.; Kim, C. S. Lignin Depolymerization and Conversion: A Review of Thermochemical Methods. Chem. Eng. Technol. 2011, 34, 29-41.

(11) Mathias, A. L. Produção de Vanilina a Partir da Lenhina: Estudo Cinético e do Processo; Faculdade de Engenharia da Universidade do Porto, 1993.

(12) Fargues, C.; Mathias, Á.; Rodrigues, A. Kinetics of Vanillin Production from Kraft Lignin Oxidation. Ind. Eng. Chem. Res. 1996, $35,28-36$.

(13) Calvo-Flores, F. G.; Dobado, J. A. Lignin as Renewable Raw Material. ChemSusChem 2010, 3, 1227-1235.

(14) Munavalli, D. S.; Chimatadar, S. A.; Nandibewoor, S. T. Oxidation of Vanillin by a New Oxidant Diperiodatoargentate(III) in Aqueous Alkaline Medium. Ind. Eng. Chem. Res. 2007, 46, 14591464.

(15) 'T Hart, B. A.; Simons, J. M.; Shoshan, K.-S.; Bakker, N. P. M.; Labadie, R. P. Antiarthritic activity of the newly developed neutrophil oxidative burst antagonist apocynin. Free Radical Biol. Med. 1990, 9, $127-131$.

(16) Stefanska, J.; Sarniak, A.; Wlodarczyk, A.; Sokolowska, M.; Pniewska, E.; Doniec, Z.; Nowak, D.; Pawliczak, R. Apocynin reduces reactive oxygen species concentrations in exhaled breath condensate in asthmatics. Exp. Lung Res. 2012, 38, 90-99.

(17) Stefanska, J.; Sarniak, A.; Wlodarczyk, A.; Sokolowska, M.; Doniec, Z.; Bialasiewicz, P.; Nowak, D.; Pawliczak, R. Hydrogen peroxide and nitrite reduction in exhaled breath condensate of COPD patients. Pulm. Pharmacol. Ther. 2012, 25, 343-348.

(18) Yancheva, D.; Velcheva, E.; Glavcheva, Z.; Stamboliyska, B.; Smelcerovic, A. Insights in the radical scavenging mechanism of syringaldehyde and generation of its anion. J. Mol. Struct. 2016, 1108, $552-559$. 
(19) Karthik, G.; Angappan, M.; VijayaKumar, A.; Natarajapillai, S. Syringic acid exerts antiangiogenic activity by downregulation of VEGF in zebrafish embryos. Biomed. Prev. Nutr. 2014, 4, 203-208.

(20) Srinivasulu, C.; Ramgopal, M.; Ramanjaneyulu, G.; Anuradha, C. M.; Suresh Kumar, C. Syringic acid (SA) - A Review of Its Occurrence, Biosynthesis, Pharmacological and Industrial Importance. Biomed. Pharmacother. 2018, 108, 547-557.

(21) Baker, C. J.; Mock, N. M.; Whitaker, B. D.; Roberts, D. P.; Rice, C. P.; Deahl, K. L.; Aver'yanov, A. A. Involvement of acetosyringone in plant-pathogen recognition. Biochem. Biophys. Res. Commun. 2005, $328,130-136$.

(22) Hocking, M. B. Vanillin: Synthetic Flavoring from Spent Sulfite Liquor. J. Chem. Educ. 1997, 74, No. 1055.

(23) Tomlinson, G. H.; Hibbert, H. Studies on Lignin and Related Compounds. XXIV. The Formation of Vanillin from Waste Sulfite Liquor. J. Am. Chem. Soc. 1936, 58, 345-348.

(24) Sandborn, L. T.; Salvesen, J. R.; Howard, G. C. Process of Making Vanillin. U.S. Patent US2057117A, 1936.

(25) da Silva, E. A. B.; Zabkova, M.; Araújo, J. D.; Cateto, C. A.; Barreiro, F.; Belgacem, M. N.; Rodrigues, A. E. In Valorisation of Kraft Lignin by Producing Vanillin and Lignin-based Polyurethanes: Use of the Biorefinery Concept, Proceedings of the Nordic Wood Biorefinery Conference, Helsinki, Finland, 2009; p 8.

(26) Aarabi, A.; Mizani, M.; Honarvar, M. The use of sugar beet pulp lignin for the production of vanillin. Int. J. Biol. Macromol. 2017, 94, 345-354.

(27) Mathias, A. L.; Rodrigues, A. E. Production of Vanillin by Oxidation of Pine Kraft Lignins with Oxygen. Holzforschung 1995, 49, 273-278.

(28) Jose, T. P.; Nandibewoor, S. T.; Tuwar, S. M. Kinetics and Mechanism of the Oxidation of Vanillin by Hexacyanoferrate(III) in Aqueous Alkaline Medium. J. Solution Chem. 2006, 35, 51-62.

(29) Fawzy, A.; Zaafarany, I.; Althagafi, I.; Alfahemi, J.; Morad, M. Kinetics and Mechanism of Oxidation of Vanillin by Permanganate in Neutral Medium and the Effect of Different Transition Metal Ion Catalysts. Austin Chem. Eng. 2016, 3, 1026-1032.

(30) Benitez, F. J.; Beltran-Heredia, J.; Acero, J. L. Oxidation of Vanillic acid as a model of polyphenolic compounds in olive oil wastewaters. III. Combined UV radiation-hydrogen peroxide oxidation. Toxicol. Environ. Chem. 1996, 56, 199-210.

(31) Liu, C.; Zeng, C. Heterogeneous kinetics of methoxyphenols in the $\mathrm{OH}$-initiated reactions under different experimental conditions. Chemosphere 2018, 209, 560-567.

(32) Alunga, K. R.; Ye, Y. Y.; Li, S. R.; Wang, D.; Liu, Y. Q. Catalytic oxidation of lignin-acetoderivatives: a potential new recovery route for value-added aromatic aldehydes from acetoderivatives. Catal. Sci. Technol. 2015, 5, 3746-3753.

(33) Benitez, F. J.; Real, F. J.; Acero, J. L.; Leal, A. I.; Cotilla, S. Oxidation of Acetovanillone by Photochemical Processes and Hydroxyl Radicals. J. Environ. Sci. Health, Part A: Environ. Sci. Eng. 2005, 40, 2153-2169.

(34) Ansaloni, S.; Russo, N.; Pirone, R. Wet Air Oxidation of Acetovanillone over $\mathrm{LaFeO}_{3}$ as Catalyst: A Model Reaction for Lignin Valorization. J. Adv. Catal. Sci. Technol. 2016, 3, 49-62.

(35) Singh, K.; Kumar, A. Kinetics of complex formation of Fe(III) with syringic acid: Experimental and theoretical study. Food Chem. 2018, 265, 96-100.

(36) Sales, F. G.; Maranhão, L. C. A.; Lima Filho, N. M.; Abreu, C. A. M. Kinetic Evaluation and Modeling of Lignin Catalytic Wet Oxidation to Selective Production of Aromatic Aldehydes. Ind. Eng. Chem. Res. 2006, 45, 6627-6631.

(37) Pinto, P. C. R.; Silva, E. B.; Rodrigues, A. E. Comparative Study of Solid-Phase Extraction and Liquid-Liquid Extraction for the Reliable Quantification of High Value Added Compounds from Oxidation Processes of Wood-Derived Lignin. Ind. Eng. Chem. Res. 2010, 49, 12311-12318.

(38) Fargues, C.; Mathias, A.; Silva, J.; Rodrigues, A. Kinetics of Vanillin Oxidation. Chem. Eng. Technol. 1996, 19, 127-136.
(39) Fung, B. S. K.; Hrutfiord, B. F. Oxidation of Acetovantillone to Vanillin. U.S. Patent US4691061, 1987.

(40) Wallick, S. A.; Sarkanen, K. V. Effect of $\mathrm{pH}$ on the autoxidation kinetics of vanillin. Wood Sci. Technol. 1983, 17, 107-116.

(41) Kalyani, A. G.; Jamunarani, R. Oxidation of Syringaldehyde by Alkaline Hexacyanoferrate (III) - A Kinetic and Mechanistic Study. Chem. Sci. Rev. Lett. 2015, 4, 695-702. 